\title{
A Review on Photovoltaic Systems: Mechanisms and Methods for Irradiation Tracking and Prediction
}

\author{
Hermes José Loschi, Yuzo Iano, Julio León, Angelo Moretti, Fabrizzio Daibert Conte, \\ Horácio Braga \\ Department of Communications, Faculty of Electrical and Computer Engineering, State University of Campinas \\ (UNICAMP), Campinas, Brazil \\ Email: eng.hermes.loschi@ieee.org, yuzo@decom.fee.unicamp.br, fabrizzio.conte.br@ieee.org, \\ j.leon@decom.fee.unicamp.br, angelomorett@hotmail.com, horaciobbraga@hotmail.com
}

Received 17 May 2015; accepted 11 July 2015; published 15 July 2015

Copyright (C) 2015 by authors and Scientific Research Publishing Inc.

This work is licensed under the Creative Commons Attribution International License (CC BY). http://creativecommons.org/licenses/by/4.0/

(c) (i) Open Access

\section{Abstract}

Solar energy is the raw material and main source for several applications of renewable energy systems; thus, knowledge about the intensity of solar irradiation is essential for efficiency of these systems. Electric energy sources capable of meeting the growing demands of society with minimal impacts to the environment and high efficiency have been object of research in the last decade. In this context, the conversion of sunlight into electricity through photovoltaic cells has become one of the most encouraged and used resources in the world. However, the most unpredictable factor, which hampers capturing solar irradiation, preventing a proper conversion of sunlight into electricity, is the presence of clouds in the sky. Many methods of tracking and prediction of irradiation were proposed to increase efficiency in the production of energy by photovoltaic cells. This article presents an updated review on the mechanisms used for tracking and irradiation prediction, and their respective methods. It begins with a brief review on photovoltaic systems and classification of its mechanisms. Then, it presents a detailed overview on the evolution of mechanisms and their corresponding methods for tracking and irradiation prediction. Finally, the authors conclude with an analysis of performance efficiency of the mechanisms and their corresponding methods presented, describing the pros and cons of the most significant proposals for tracking and irradiation prediction.

\section{Keywords}

Photovoltaic (PV), Tracking, Irradiation, Prediction, Closed-Loop, Open-Loop

How to cite this paper: Loschi, H.J., Iano, Y., León, J., Moretti, A., Conte, F.D. and Braga, H. (2015) A Review on Photovoltaic Systems: Mechanisms and Methods for Irradiation Tracking and Prediction. Smart Grid and Renewable Energy, 6, $187-208$. 


\section{Introduction}

Electric power generation in most societies depends on the limited fossil fuel sources. Among the main sources of renewable energy, solar energy stands out as one of the most promising. Photovoltaic (PV) systems represent solutions for utilizing solar energy by society. The main elements of the PV systems are PV cells connected into modules. These modules convert sunlight directly into electricity. The efficiency of this conversion depends on the solar irradiation that reaches the surface of the PV cells, the quality and type of PV cell, its temperature, connections between cells and PV modules, adaptation of the impedance between PV modules with the DC/DC converters, and quality of AC inverters [1] [2].

The solar irradiation that reaches the Earth's surface may not be used as a parameter to control decisionmaking of a PV system, since it mainly depends on, among other factors, atmospheric conditions. However, the solar irradiation that reaches the surface of the PV cells in the form of direct or diffused irradiation can influence the decision making for control of the PV system. During sunny days with clear skies, the direct irradiation in the form of rays represents the main contribution to the total irradiation. The available solar irradiation that reaches the surface of the PV modules is greater when the surface of the modules is perpendicular to the direction of the Sun's rays, which can happen through the use of a tracking system or irradiation prediction [1] [2].

An overview of PV cell technologies and their efficiencies are presented in [3] [4], while the impact of temperature on the efficiency of PV cells is discussed in [5] [6]. When the temperature of the solar irradiation that reaches the surface of the PV cell is suitable, the conversion efficiency of energy in cells connected in PV modules depends mainly on the impedance matching. This method is well known as the maximum power point tracking (MPPT). Some solutions for the MPPT are presented in [2] [7].

The use of tracking systems or prediction is not essential to the operation of a PV module; however, without the presence of any, its performance is greatly reduced. It is through tracking systems or irradiation prediction that a gain in energy production through the PV modules can be achieved. When deploying, some issues such as cost, reliability, energy consumption and maintenance must be deeply considered. However, the option "Feed-in Tariffs" has become a great incentive for operators and consumers to become micro or mini home generators [2] [8]. In this scenario the knowledge and the ability to track or predict the amount of solar irradiation are essential to plan a strategy for optimized operation before installation.

Tracking systems of irradiation are mechatronics mechanisms, containing electrical and mechanical equipment and technology of information, and generally have the following characteristics [2] [9]:

- Sole metal structure or dedicated to each PV module;

- One or two motors/actuators;

- Devices for detection of light;

- Autonomous or auxiliary power supply;

- Continuous or step by step movement;

- Orientation with/without adjusting the angle of inclination.

Irradiation prediction systems work integrated with tracking systems as feedback; dispensing, in many cases, the use of any light-detecting devices. In operations with tracking and prediction mechanisms, different measuring equipment and techniques for cloud classification are used. The measuring instruments can be classified into [2] [10]:

- Ground instruments;

- Integrated instruments in the satellite.

The methods used software-based algorithms for measurement, calculation and prediction of solar irradiance, and evaluation of the clouds for classification, ranging from the simplest ones using techniques to limit or rule base to the most complicated ones, consisting of monitoring methods of neural networks using numerous features [10].

The application of tracking technologies or prediction enables improvements in PV systems, such as: (1) prediction of energy production in the systems; (2) regulation of systems; (3) better design for systems and energy storage units; (4) resource assessment calculations for a specific area and; finally, (5) increase in energy production [2] [10].

Several methods to calculate the solar irradiation, either based on equations or other more complex models, have been developed in the last decades. The main factors used for calculating the solar irradiation are: (1) extraterrestrial radiation; (2) declination; (3) insolation rate (duration over the day, maximum sunlight); (4) air temperature; (5) albedo of the Earth's surface; (6) relative humidity; (7) cloudiness; (8) precipitation; (9) evapo- 
ration; (10) composition of the atmosphere; (11) optical depth; (12) geographic location and (13) the ground temperature [2] [10].

The ideal concept for a tracking system or prediction parts from the premise where the PV modules are perpendicular to the available irradiation, accurately pointing towards the Sun, and compensating for both the variations in the elevation angle (during the day) and on changes in the azimuth angle [2] [9].

The tracking systems or prediction, in their vast majority, can operate as closed or open-loop systems. Closed-loop systems use the concept of feedback through light detection devices to position the system in relation to the Sun [1] [9] [11]. In recent cases, monitoring of the movement of clouds is used for data collection, positioning and subsequent decision making for PV systems [10] [12]. Open-loop systems do not require the use of feedback, and work through mathematical algorithms that calculate the astronomical coordinates to determine the ideal positioning [2] [11].

The objective of this paper is to provide a detailed review of the mechanisms used for tracking and irradiation prediction, and their respective methods, by analyzing their technical differences and the equipment used. The task begins with a brief introduction to the concept of tracking mechanisms and methods, as well as introduces the types of clouds and their effect on the solar irradiation incidence on the ground's surface. The third chapter presents an evolution and a detailed description of the mechanisms, and their corresponding methods used in passive tracking (mechanical).

The following chapter presents the same, but this time for active tracking (electrical) systems. After these two descriptive chapters, we introduce the equipment used for irradiation prediction and proceed to describe the mechanisms and methods using PV systems integrated with prediction methods. Finally, the discussion and conclusions are presented, highlighting the applicability of these mechanisms and methods for distributed generation of electricity.

\section{Mechanism Classification Parameters}

Tracking and prediction mechanisms must be, from their conception, trustworthy within a range of accuracy to track and predict irradiation throughout the day, including cloudy days, and to return to its original position at the end of the day, in addition to being used as a protection mechanism, diverting the PV system in cases of overheating, wind gusts, rain of hailstones and possible flaws [4].

The appropriate classification of the clouds is the basic requirement to predict and then track the incident solar radiation, which may have its irradiance capability affected by different reasons, such as [10]:

- Different types of clouds: a different proportion of incident solar irradiation passes through them;

- There is a direct correlation between the incidence of solar irradiation with the size and opacity of the cloud;

- Ice crystals and water droplets have a different impact on the absorption and scattering of incident solar irradiation;

- Due to clouds having different altitudes depending on their type, they may be affected by difference in air flow, thus moving in different directions and at different speeds;

- In addition, different climatic conditions due to the difference in altitude may drive the clouds to have a divergent development over time; even inducing rain.

Through the knowledge of the cloud type, size, movement and development, one can calculate and predict the solar irradiation that can reach a PV system among other factors, making it possible to calculate the energy production at the given location [10].

\section{Passive Tracking}

Passive tracking is based on thermal expansion in materials. Usually, a fluid (liquid or gas) is initially deployed in two reservoirs installed opposite each other; making it possible to vaporize the fluid, in accordance with the apparent motion of the sun. The system movement is possible because there is a connection between the tanks carrying the condensated fluid, from the reservoir of highest incidence to the smaller one. American companies like Zomewords have developed passive tracking mechanisms since 1969 [13].

In 1994, Poulek developed a passive tracking system based on axis actuators with the idea of Shape Memory Alloy (SMA). The SMA actuator can be easily deformed at relatively low temperatures of operation (below $70^{\circ} \mathrm{C}$ ), returning to its original shape when heated above a certain specific temperature. During the thermal cycles, the SMA actuator operates as a heat engine. The efficiency of SMA actuators ( $2 \%)$ is about two orders 
of magnitude superior to bimetallic actuators (that can be theoretically used). During laboratory and field tests, the tracker had its design project approved [14].

In 2004 researchers Clifford and Eastwood developed a low-cost passive tracking system for equatorial regions with an efficiency gain of $23 \%$ over traditional fixed PV modules. In this paper, it is possible to observe the benefits of tracking and its high potential for applications in various geographical locations. However, the proposed tracking system considers only one axis regarding the sun's apparent motion; thus, this system cannot compensate for the variations caused by the latitude angle along the changes of seasons. The design of passive tracking mechanism incorporates two bimetallic strips (bulkheads) made of aluminum and steel, positioned on a wooden structure, symmetrically on both sides, with a central horizontal axis, similar to the drawing shown in the Figure 1 [15].

During the following years, with the exponential evolution of electronic technologies and increasing awareness about the use of PV systems for generating electricity, research in the field of passive tracking systems have become scarce. It appears that the literature shows now an interest to present technological solutions in the form of new fluids/gases to improve the process.

Research by PRODETEC's (Graduate Program of Technology Development) researcher Castañeda in 2011 presents a new proposal using a pressurized fluid (ethoxyethane), also known as diethyl ether, for being a substance of highly volatility [16]. His work shows clearly the benefits of the tracking system [15], emphasizing the application of diethyl ether and comparing it with other fluids by conducting field tests with the other proposed substances [16].

Passive tracking mechanisms are viable in geographic locations near the equator due to the high solar availability and minimum variation in azimuth and elevation angle, and for complementary applications to the primary power generation, or isolated applications. However, the extended use of these systems becomes unaffordable in addition of requiring knowledge and careful handling of the fluids by the operator. It is worth mentioning that the system's operation depends on the thermal expansion process; thus, in adverse weather conditions, the efficiency of the system will be fully compromised.

\section{Active Tracking}

In 1975, one of the first active tracking systems was presented by McFee. It is an algorithm that was developed to calculate the total power and the distribution of the flux density in a central receiver of a solar power system. This was accomplished through the subdivision of each mirror into 484 elements, and the calculation is performed by summing the contribution of each element. The position of the sun was determined with error tolerance ranging from $0.5^{\circ}$ to $1^{\circ}$ [17].

Most active tracking systems can be classified based on their control logic: date and time methods, microprocessor-based, electric-optical sensor-based and auxiliary PV cells.

Active tracking systems that use micro-processing and electro-optical sensors are usually composed of at least a couple of photoresistors or PV cells that have the same irradiation requirements being electrically balanced,

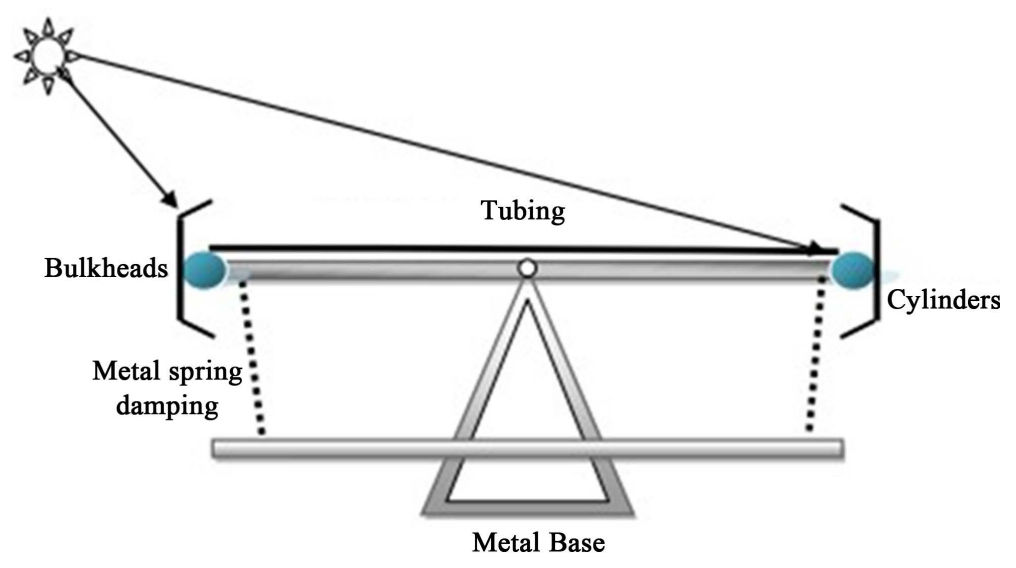

Figure 1. A tracking system using two identical cylinders, connected by a tube, filled with a fluid under pressure [16]. 
avoiding any control signal in antiparallel to the drive motor, basically being matched. In the systems with auxiliary bifacial solar cells, these cells detect and trigger the system to move to the desired position. In systems based on date and time control, a computer calculates the position of the sun through mathematical algorithms, generating system control signals [9].

A. Microprocessor and electric-optical sensor

The closed loop circuits in tracking systems are based on the principles of control through feedback. In these systems, the number of inputs is derived from sensors, which detect relevant parameters of the sun and send them to a controller. The parameters are then analyzed by the controller which governs the "outputs". In microprocessor tracking systems, with the use of electric-optical sensors, a different control signal (Figure 2(a)) is used to trigger the engine and to orient the PV modules in the direction light incidence over the electric-optical sensors becomes equal and balanced. Moreover, photodiodes can be mounted on inclined planes, aiming to increase the sensitivity of the photocurrent (Figure 2(b)). Often, in several applications, a shading device is presented as a tube collimator (Figure 2(c)) [18].

High precision tracking systems are usually designed for solar power arrays [18]. However, with the current exponential evolution and application of PV systems for generating electricity, these tracking systems are being widely used overall.

In 1984, Zogbi developed a two-axis tracking system (solar elevation and azimuth angle). Four electric-optical sensors were placed in each quadrant formed by two rectangular plans crossing one another in a line. The control unit consists of an amplifier and other electronic components to compare the received signals from each pair of sensors and to operate the two motors for the system drive. The system goes back to its initial position at the beginning of the night. If the output of one of the sensors is greater than the threshold set, the motor is activated by an amplifier until the signals are smaller than the threshold. The authors conclude that the prototype built operates successfully under variable light intensity conditions [19].

In 1986, Rumala developed a closed loop tracking system, based on the shadow method. Photoresistive sensors were placed on a platform under a pair of cylinders mounted back-to-back E-W (East-West) and N-S (North-South). The rigid platform has two articulated arms, powered by engine's camshaft. A signal conditioning circuit with a low pass filter feeding an amplifier sends signals to drive a servomotor for correcting and aligning the system through the difference of detected solar irradiation. The system remains in that position until sunset; it then auto-starts in the morning [20].

Kalogirou presented, for the first time, in 1996, a single-axis tracking system using three light dependent resistors (LDR). The first LDR detects the focus state of collector, while the second and third LDRs were designed to detect the presence (or absence) of shadowing and discriminate the information between day and night respectively. The signals from the output of the three LDRs are sent to an electronic control unit that triggers a low speed DC motor with $12 \mathrm{~V}_{\mathrm{DC}}$, keeping the collector perpendicular to the sun (Figure 3) [21].

In 1998, Khalifa developed a two-axis tracking system to improve the thermal performance of a parabolic concentrator. The system is designed to track the position of the sun every three minutes in relation to the hori-

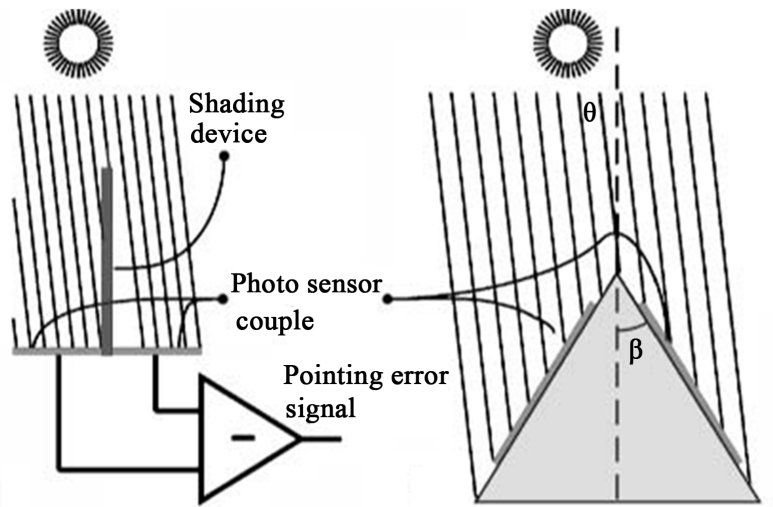

(a) (b)

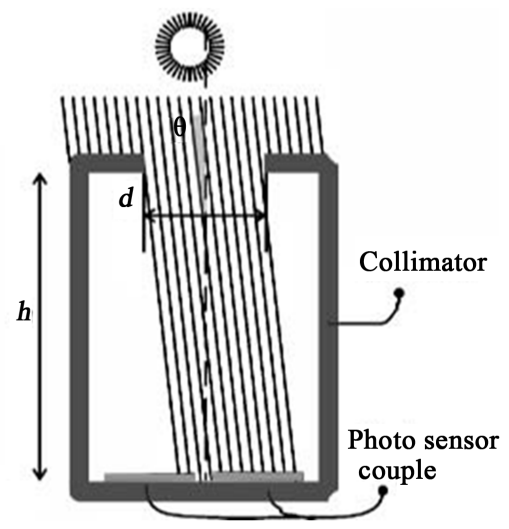

(c)

Figure 2. (a) Sensors pointing towards the Sun; (b) Photodiode sensors mounted in an inclined plane; (c) Precise view angle of the sun using the collimator concept [18]. 


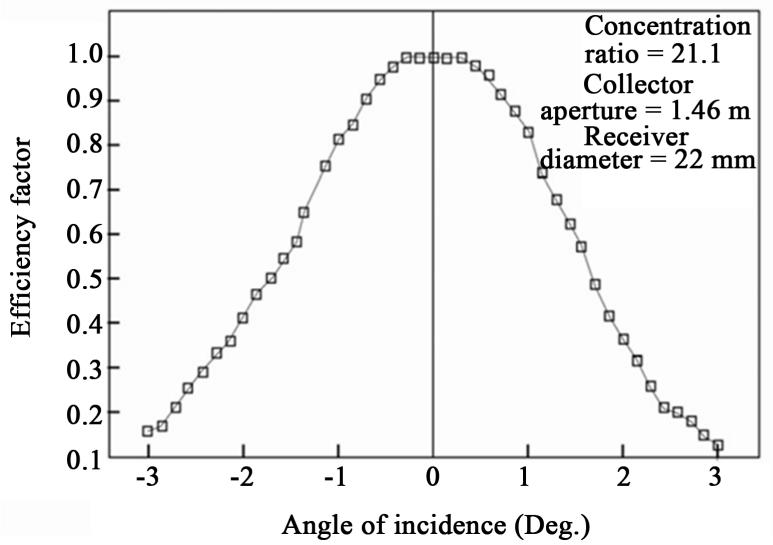

(a)

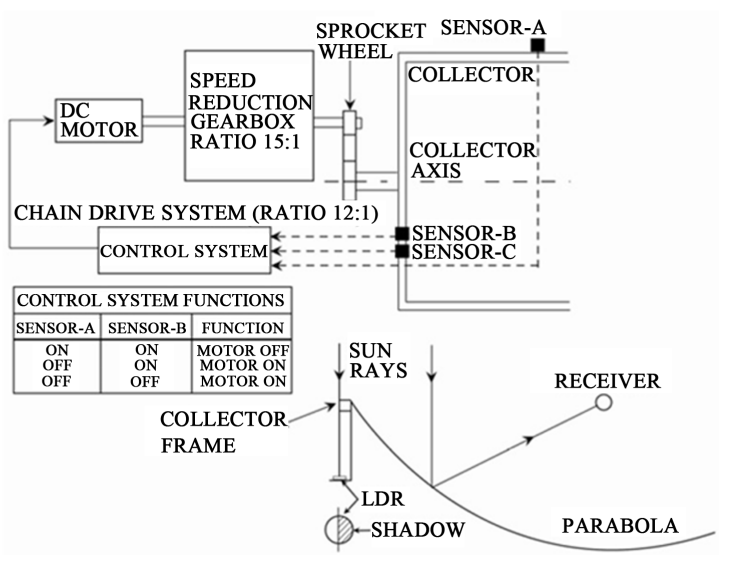

(b)

Figure 3. (a) Efficiency factor vs. angle of incidence; (b) Tracking mechanism conceptual diagram [21].

zontal plane and four minutes in the vertical plane. As shown in Figure 4, the tracking system was composed of two identical subsystems, one for each axis, with each subsystem consisting of two adjacent phototransistors. In tracking mode, the difference in voltage signals from the phototransistor is amplified and used as a command signal to trigger the collector around its axis until the voltage difference is reduced to zero, indicating that the collector is perpendicular to the incidence of solar rays. It has been shown that the tracking system had a power consumption of only $0.5 \mathrm{~W}$ and increased production by about $75 \%$ in comparison with a fixed collector of equivalent dimensions [22].

Zeroual has developed a tracking system with electric-optical sensors to control a water heating system. Various parameters such as wind speed, pressure and temperature of the environment were also tracked. The field tests in long periods and in varying conditions verified the accuracy of the system. Figure 5 represents an schematic block diagram of the tracking system [23].

In 1999, Yousef proposed a tracking system where the nonlinear dynamics of the tracking mechanism were controlled using fuzzy logic, a control algorithm implemented in a computer and supported by an interface card with sensors for data acquisition. The motor was driven by signal conditioning circuits with serial communication interfaces [24].

In 2003, Urban presented a 5W PV module for an autonomous tracking system with a capacity of $2.6 \mathrm{~kW}$. The tracking system was developed to track the position of the sun autonomously in the directions of solar elevation and azimuth angles. The system is driven by two $12 \mathrm{~V}_{\mathrm{DC}}$ motors, each with a power consumption of $36 \mathrm{~W}$, and both being powered by a single electrolytic capacitor loaded by the PV module [25].

Around 2004, Roth developed a solar tracking system with a Pyrheliometer (an irradiance measuring instrument) used to direct solar irradiance measurements. The closed loop system consists in four quadrants of photodiodes (Figure 6(a)) to detect the position of the sun, where the DC motors were used to drive the platform instruments while keeping the irradiation in the center, between the four quadrants. Note that the cross coupling of AA and BB (Figure 6(b)) is virtually zero due to the arrangement of the orthogonal axis and the sensor's parallel mounting [26] [27].

In that same year, Berenguel developed an automatic correction in a heliostat system based on artificial vision techniques with a black and white CCD camera (charge-coupled device) (Figure 7(a)). In the proposed approach, solar images, projected from the heliostat, were captured with a resolution of $640 \times 380$ or $768 \times 576$ (Figure 7(b)), providing the images, in real-time, to a computer through the frame-grabber with a PCI (Peripheral Component Interconnect) bus. The images were compared with reference images of the sun's incident rays in the direction normal to the surface of the heliostat. The difference between the images was used to compute a command signal for heliostat control system, triggering the servomotor, keeping the system surfaces perpendicular to the sun's rays [28].

In 2007, Huang designed a tracking mechanism based on single axis adjustment in three fixed angles: morning, noon and evening. The mechanism includes a single pole for support and an adjustable platform for inclination. The structure of the PV modules is driven by a motor and a solar positioning sensor. The solar positioning 


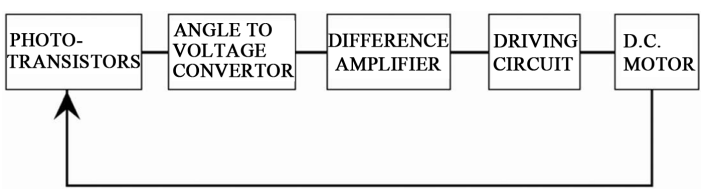

Figure 4. Block diagram of the tracking system [22].

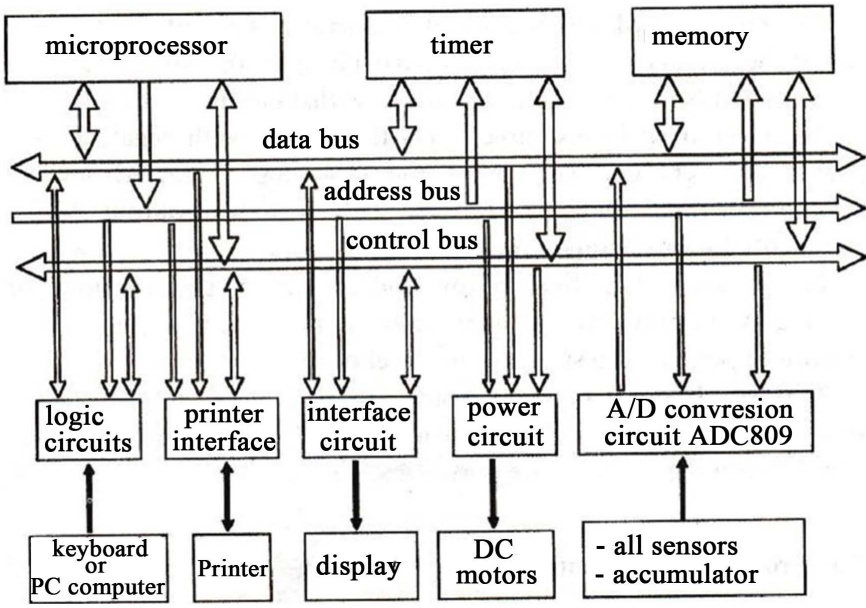

Figure 5. Block diagram of the tracking system presented in [23].

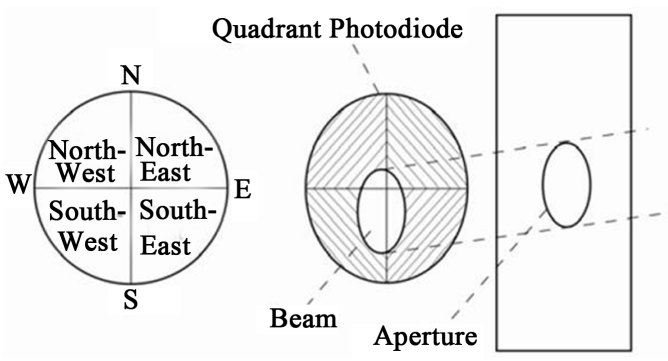

(a)

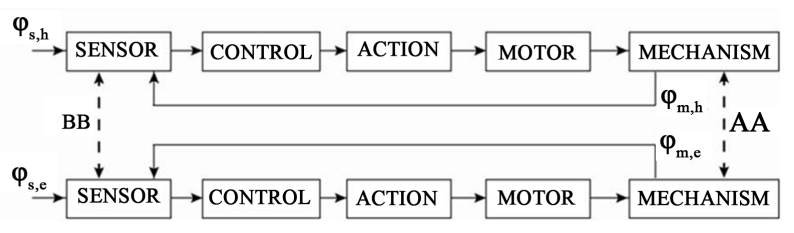

(b)

Figure 6. (a) Four-quadrant sensor and (b) Transfer function for both axis [26].

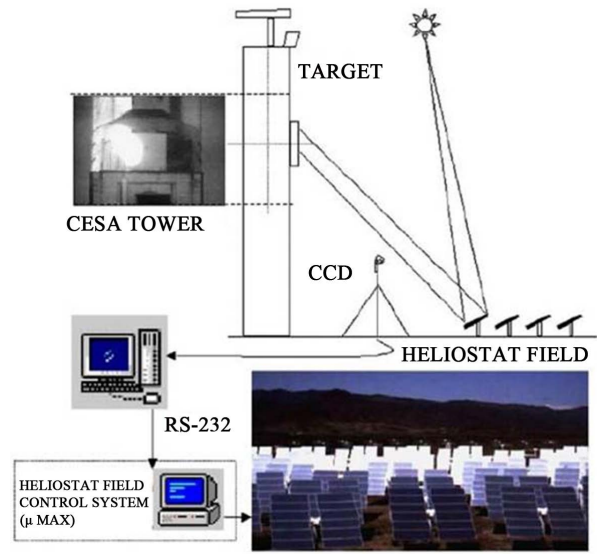

(a)

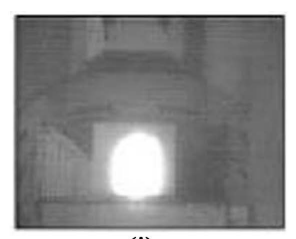

(i)

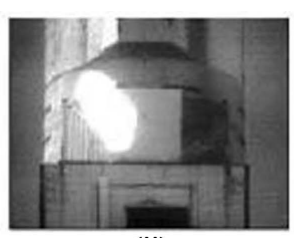

(ii)

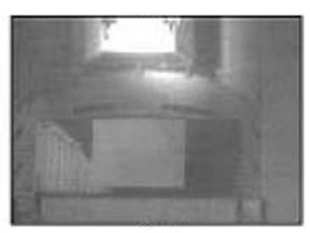

(iii)

(b)

Figure 7. (a) Schematic illustration of the heliostat control system [28]; (b) Photographs that show different shapes of projected images by the heliostat on the target plane: (i) centered ellipsoids (changes in the shape of the ellipsoid during the daytime) (ii) ellipsoid out of boundaries due to tracking errors (iii) [28]. 
sensor consists of two photodiode elements divided by a vertical shading plate. Three touch-sensitive switches were mounted on the frame transmission gear to signal the end of course to control circuit. When performing tests for different inclination angles at different latitudes, it was concluded that the optimum angle is $50^{\circ}$, independent of latitude. From the total energy calculation results, an increase in PV power generation of $24.5 \%$ was achieved, compared to PV fixed modules [29].

Rubio discussed the design and implementation of a two-axis tracking system using a combination of an open-loop strategy with a microprocessor, where the controller is based on a model of solar movement; and a closed-loop strategy, with a controller based on an electric-optical sensor's feedback. The instantaneous power generated by the arrays is measured by a sensor, which emits a signal proportional to this energy. A proportional-integral control strategy (PI) for each coordinates used to control the input variables independently (Figure 8). The electric energy generated using hybrid strategy is, on average, 55\% higher than an open circuit strategy [30].

In 2009, Chou developed a measuring system and solar orientation with integrated PV cells. The methodology for the calculation of solar orientation was developed considering the latitude and the solar angles were determined from the output voltages measured in the inclined PV cells. Three types of metering systems are considered: a single cell, a double cell, and a “quadrant” cell type. In the quadrant cell type measurement system, a variation in the angles of azimuth and solar elevation generates a change in E-W (East-West) or N-S (NorthSouth) in the PV cells respectively, in their comparative voltage outputs. The inclination of PV cells in an angle of $45^{\circ}$ ensures that the voltage will be enough so that the solar elevation and azimuth angles can be predicted with accuracy [31].

In 2011, Huang has developed a tracking system of an axis and three positions (1A-3P), developed for measuring daily (and long-term) energy generation in a PV system. A comparative test using a fixed PV system and a PV system with 1A-3P tracking was performed with two autonomous and identical solar powered LED-based lighting systems. The field test showed that $1 \mathrm{~A}-3 \mathrm{P}$ tracking has an increase in power generation of $35.8 \%$ of electricity when compared with the fixed PV system in partially cloudy days with an irradiation of 11.7 $\mathrm{MJ} / \mathrm{m}^{2}$ - day; or $35.6 \%$ in days of clear weather with an irradiation of $18.5 \mathrm{MJ} / \mathrm{m}^{2} \cdot$ day. This indicates that $1 \mathrm{~A}-3 \mathrm{P}$ tracking can operate very closely to a two-axis tracking system [32].

Jeong developed a PV system using photodiodes for tracking. The performance of the system was tested and compared to a PV system fixed. Based on the results obtained, it can be stated that the proposed solution was effective and showed interesting advantages from the point of view of their practical applications for PV systems in larger structures. The experiments were conducted in Gwang-Ju City, South Korea. The developed system has generated surplus energy ranging from $18.3 \%$ to $34 \%$ during the winter season [33].

In 2014, More presents the development of a tracking system that positions the PV module in proper orientation to the sun in order to receive always direct irradiation. The prototype is developed around a programmed microcontroller including a sensor interface and responsible for the motor control based on the sun's movement pattern. The tests' results presented an increase in electric power production of $15 \%$ to $25 \%$ in comparison to fixed PV modules [34].
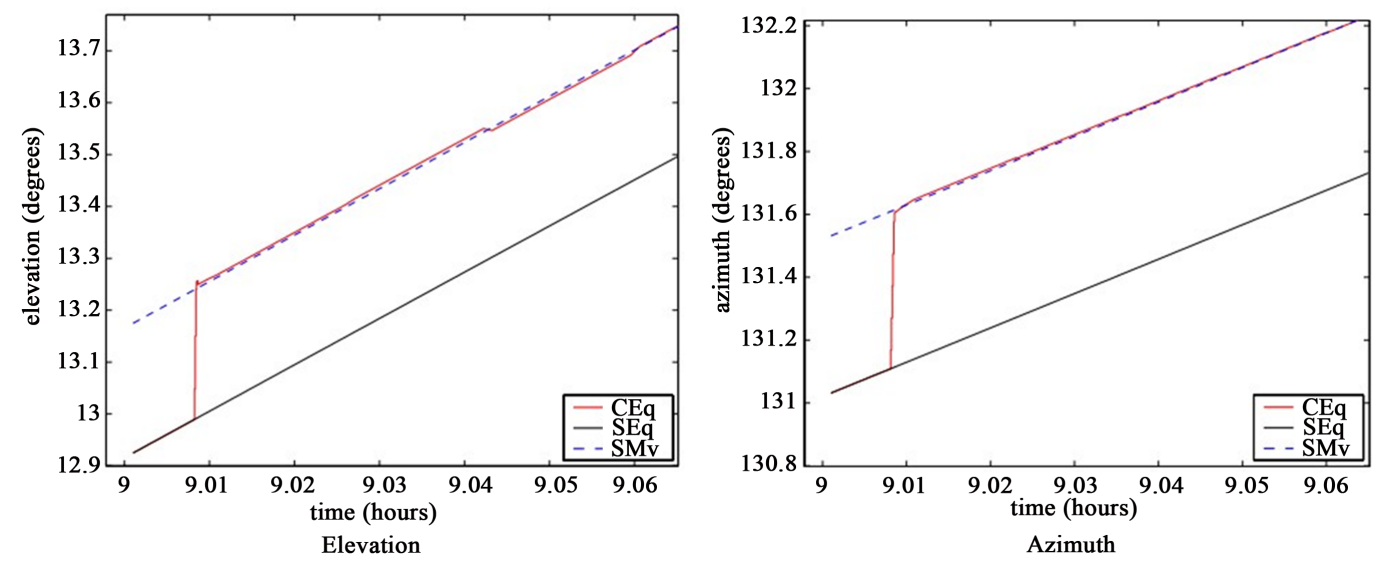

Figure 8. Evolution of coordinates for an open-loop strategy with a microprocessor [30]. 
At the same time, a new solar tracking system was developed in Afyon Kocatepe University to maximize the efficiency of different PV modules. The system consists of two main parts: the mechanical part and the control part. The mechanical part of the system has the ability to both move in the vertical plane and the horizontal planes. The control part enables remote access to the system. The results indicate that automatic tracking with the help of LDR is the best way to improve efficiency. However, one of the concerns presented is that the power consumption by the tracking system is too high. Some strategies are presented for resolution of this issue. For example, in the case of the fourth strategy [28], the system will only move two or three times a day. Therefore, the power consumption of the tracking system will be much smaller than the fifth strategy presented. The authors propose that different strategies should be considered for cloudy days and sunny days [35].

Mumtahina developed a hybrid prototype with hardware and software, applied to tracking systems, capable of providing automatically the best alignment of a PV module with the sun for maximum power generation. The system identifies the position of the Sun and controls movement of the PV module, keeping it perpendicular to the solar irradiation. The tests were conducted randomly between of March and August, for performance analysis. The efficiency of the solar tracking was 31\% in comparison with fixed PV modules [36].

Yilmaz developed a two axis tracking system, controlled through analytical calculations of the solar irradiation. The advantages of the proposed system are clearly discussed and compared with the results of other studies in the literature. As a result, the proposed model can easily be used for solar power plants and PV systems for a more efficient production of energy [37].

Recently, Cristian proposed to perform a comparative analysis between fixed systems and tracking systems, both being low-power and considering energy consumption. The power consumption by the solar tracking system is in the order of 50W. In order to compare the performance of both, two prototypes were constructed and investigated for 30 days. The experimental results show a significant increase in the energy produced by tracking systems (12\% to 20\%). In addition, the results obtained during days of "clear skies" show that any tracking system should be considered to limit energy consumption. Based on the results obtained during days of "partially clear sky" and the "days of overcast skies", the authors conclude that further research is necessary to minimize the variations of irradiation. In this way, the energy consumption by the tracking system associated to unnecessary rotations of PV systems can be limited [38].

B. Auxiliary photovoltaic cells

The tracking system which uses auxiliary PV cells connected directly to a magnet installed on a DC motor, fixated to a rotary axis tracking system, aims at detecting irradiation and electric power supply for the tracking system.

In 1998, Poulek developed a tracking system based on a new arrangement of PV cells connected directly to a DC motor. Figure 9 shows the principle of the tracker. The rotation axis of the tracking system is oriented in the north-south direction with accuracy of about $\pm 10 \%$. The area of auxiliary PV cell for tracing is about $2 \%$ of the area of the collectors, while excess energy produced reaches up to $40 \%$ [39].

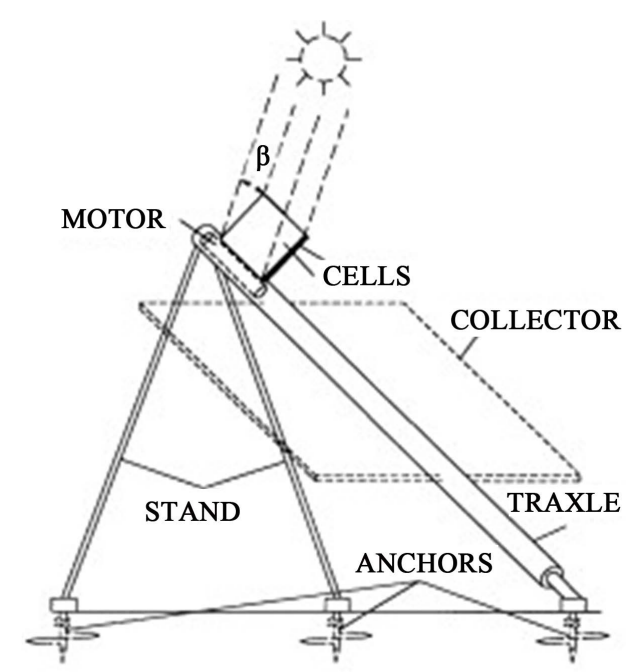

Figure 9. Rotational axis tracking system [39]. 
In 2000, Poulek develops a tracking system for use in spatial (Figure 10) and terrestrial applications. Unreliable and expensive components such as batteries and transformers were completely discarded. The system also worked at low temperatures $-40^{\circ} \mathrm{C}$. The area of auxiliary PV cell is about $1 \%$ of the total area of the PV modules. The author concludes that the tracking system has an accuracy of $\pm 5^{\circ}$ without any reduction in the energy collected. The system has the ability to take advantage of approximately $95 \%$ of the energy of an ideal tracker [40].

In 2001, Abouzeid created an active tracking system, with two opposing PV cells and a step motor controlled by a chip of programmable logic array (PLA) with a position sensor. Once the incident solar irradiation is diverted from the perpendicular main surface, two detection cells send signals to the chip and the motor starts. The programming uses Xilinx software and is saved into an EEPROM. This system can work in steps of $15^{\circ}$ or $7.5^{\circ}$ and can operate standalone without supervision [41].

In 2005 Karimov has developed an axis tracking system with four PV modules installed on a rotor. PV modules were divided into two pairs and the angle between PV modules was of $170^{\circ}$ (Figure 11) coupled in the bridge circuit, very similar to a Wheatstone bridge. If the output voltage from the modules is not equal, the voltage applied to the motor is not zero and, as a result, the engine begins to rotate. Research shows that for this tracking system, as opposed of the fixed PV modules, the output voltage in the evening and in the morning are not very different. This tracking system presents an increase in efficiency of 30\% in energy production [42].

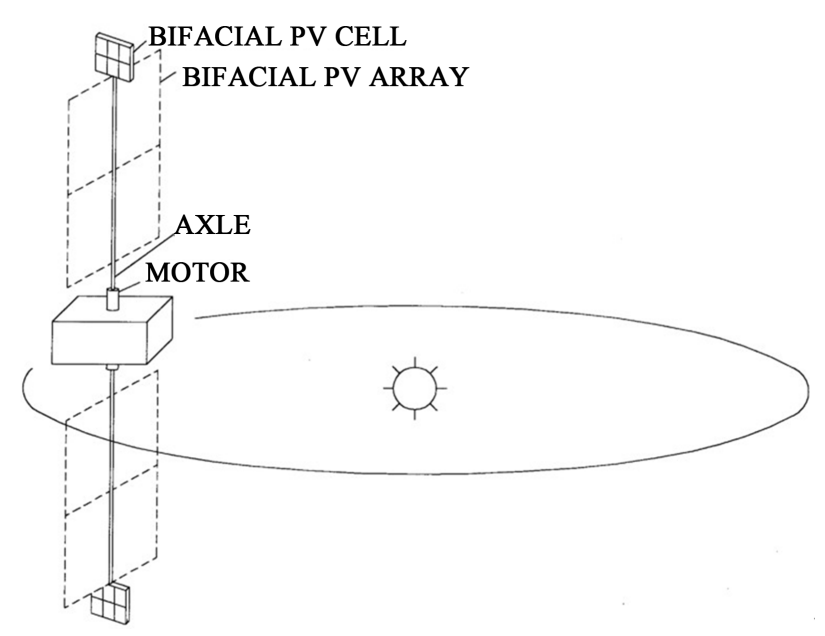

Figure 10. Tracking scheme in space or on a satellite [40].

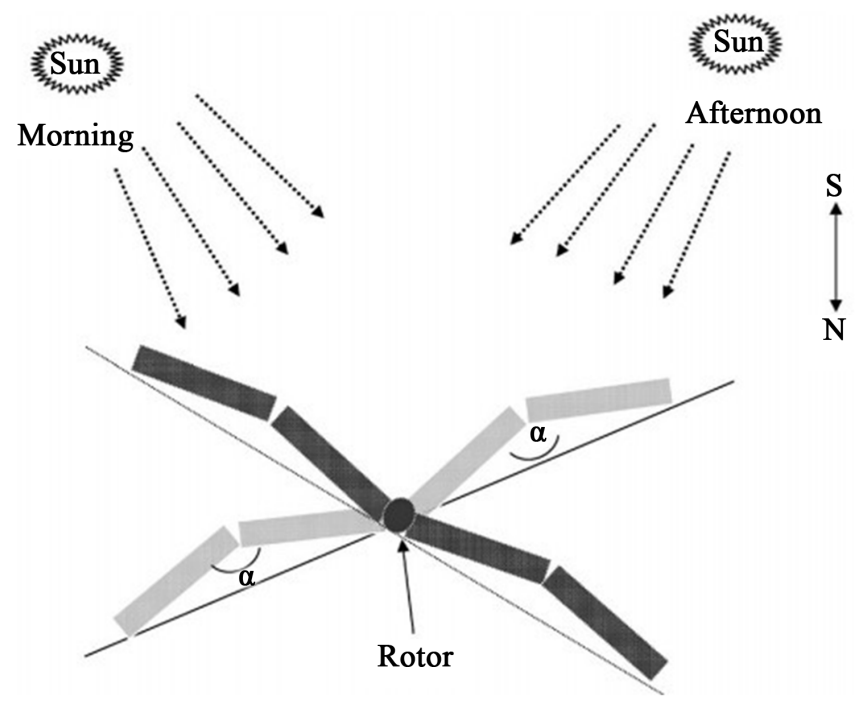

Figure 11. Position of PV modules in the morning and in the afternoon [42]. 
At the same time, Poulek presented a tracking system based on an auxiliary bifacial PV cell. This research work is the latest relevant proposal in this field and considered state-of-the-art as of this writing. The system has an average accuracy of $\pm 5^{\circ}$ installed above a solar concentrator. Two antiparallel arrangements of PV cells with $1 \%$ of the total area of solar collectors have been connected directly to a reversible DC motor. The experimental results shows that in bifacial PV modules with reduced sensitivity to temperature can increase the energy gain by $15 \%$ to $25 \%$ in comparison with fixed systems. The polar axis with auxiliary bifacial PV cell tracking provides about 50\% more energy than a fixed system with the same nominal power [43].

In 2013, Kamala developed automated environment sensitive solar tracking system to maximize solar energy harvesting economically and efficiently. It is controlled by micro-controller with necessary interface. Limit switches are used to bring back the panel to morning position after each day without human interference. Hardware implementation aims at friction free system. Worm gear mechanism is used to tolerate any environmental forces including wind or any backlash forces. Two photovoltaic cells arranged in the form of triangle, is used for sensing the position of sun. The device detects the movement of sun by comparing the intensity of light falling on two sensors. The intensity variations are determined by voltage variations in the sensors. Hardware of the system is designed with maximum friction free motion parts enabling increased overall efficiency than existing systems. It is tested by tracking $100 \mathrm{Wp}$ photovoltaic solar panel. Use of worm gears enables protection against backlash forces and it is suitable for practical applications. Control algorithms are implemented in PIC16F877A micro-controller with inbuilt ADC. It eliminates the requirement of external ADC and makes the electronic part much simpler [44].

C. Date and time algorithm

Open-loop circuits using algorithms based on date and time control operate without feedback. The system is simpler than its closed-loop counterparts and, for the most part, cheaper. This system does not monitor the results of the process that it is controlling; consequently, an open-loop system cannot correct errors or even compensate for the disruption of the system. Date and time control calculates the position of the sun from formulas or algorithms using geographical or astronomical information to drive the electric motors. However, in some cases, sensors are used to identify specific positions.

In 1978, Edwards has examined the operation of a computer based on a tracking system for parabolic collectors. The computing system changes the speed of each of the actuators collector at regular intervals throughout the day. It was concluded that, for the precise tracking of the sun, the system needs a data output to a central controller of 500 bps for 10,000 collectors [45].

In 1990, Al-Naima develops a two axis tracking system controlled via microprocessor, based on astronomical coordinates of the sun. The proposed experiments showed significant improvements in performance compared with conventional control systems of the time; the latter being controlled by sensors [46].

In 1991, Koyuncu evaluated a tracking system based on a microprocessor to control the movement of a PV module. To limit the movement of the module, the positions of East and West were limited by using two micro switches. The micro switches states were read by the microprocessor. It was concluded that the use of a tracking device to maintain the PV modules perpendicular to the sun maximizes the thermal energy obtained [47].

Soon after that, in 1993, Davies developed a solar tracking mechanism based on equatorial and ecliptic angles. In this project, the sun was regarded as a fixed point in relation to the movement of the earth; therefore, the tracking system revolves around the orbits of the earth's rotation with the same angular velocity, but in the triangular module of direction. The tracker error provided was $\pm 2^{\circ}$. The main advantage of this system is the use of a constant speed motor with precision without any applied control electronics [48].

In 1998, Jumaily analyzed the performance of a linear Fresnel lenses to concentrate the solar irradiation. The system was developed to track the sun in two dimensions (the solar elevation and azimuth angles). More than 200 tests were performed to evaluate the thermal and optical efficiency. They found that due to using two tracking dimensions and always keeping perpendicular incidence flux to the collector, the optical efficiency is maintained within about $64 \%$ efficiency [49].

In the mid-2000s, open-loop algorithms for tracking started having their uses questioned, especially when compared to closed-loop systems.

Blanco, in 2001, argued that the computational directional vectors used in open-loop systems needed to improve their accuracy in order to achieve better efficiency of solar concentration, and to become computationally simpler, minimizing the price in the tracking system. The study reviewed the current solar prediction vector algorithms; and the authors developed a new solar vector algorithm with knowledge of time and location. It has 
been shown that the algorithm's ability to determine the direction of the solar vector presents an error of $0.5^{\circ}$. Table 1 compares the solar vector generated by the prediction algorithm proposed with those calculated using the algorithm proposed in 1988 by Michalsky [50] [51].

In 2004, Abdallah proposed an electrical-mechanical two-axis tracking system controlled by an open-loop algorithm using a programmable logical controller (PLC). The proposed system incorporates two separate engines for tracking, an engine for North-South axis, horizontal, to adjust the angle of solar elevation (Figure 12(a)) and the other to East-West axis, vertical, to adjust the azimuth angle (Figure 12(b)). The experimental results indicated that the two-axis tracking system has increased the production of electric energy by $41.34 \%$ as compared with fixed PV modules [52].

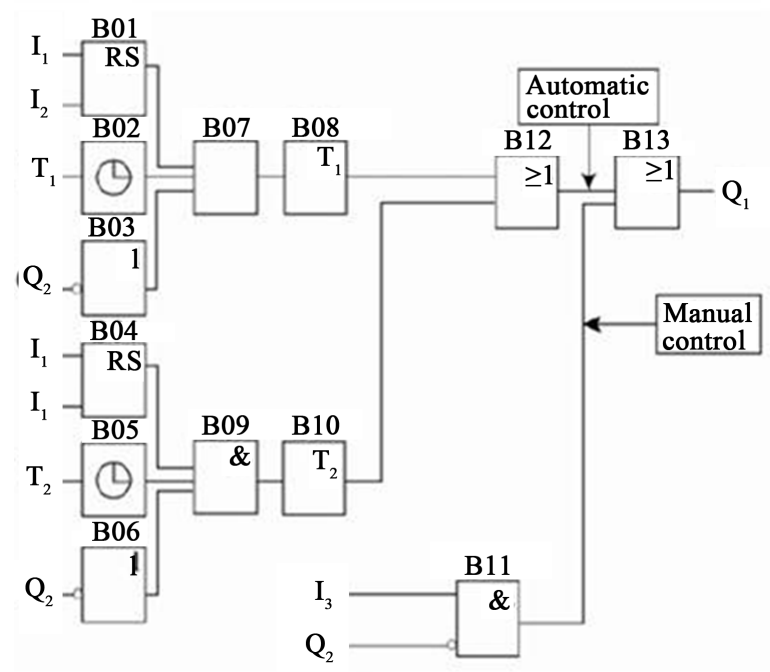

(a)

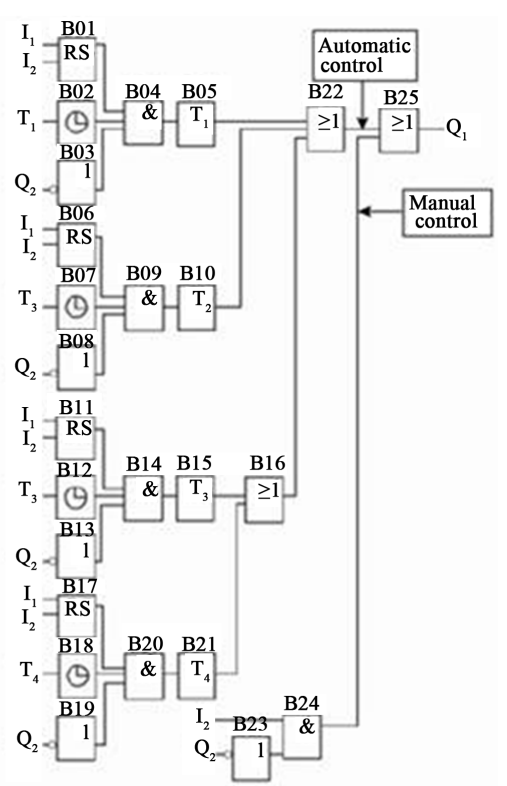

(b)

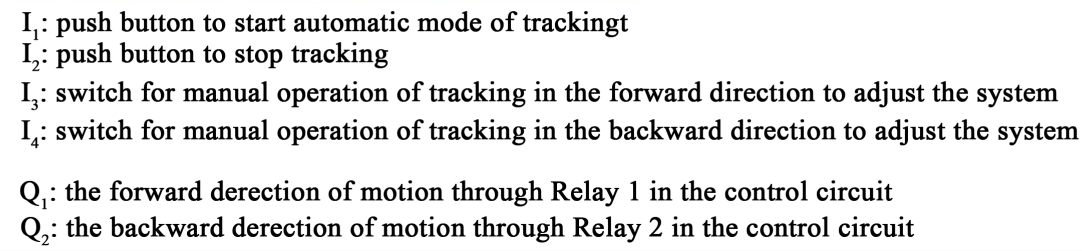

Figure 12. PLC functional program to plan the horizontal axis (a); the vertical axis (b) [52].

Table 1. Performance comparison between tracking algorithms from 1999-2015 [50].

\begin{tabular}{ccccc}
\hline & Average & Standard Deviation & Mean Deviation & Range \\
\hline $\begin{array}{c}\text { Error in Zenith Distance } \\
\text { Michalsky }\end{array}$ & -0.128 & 0.137 & 0.109 & {$[-0.6660 .340]$} \\
PAS Algorithm & -0.008 & 0.107 & 0.084 & {$[-0.3960 .366]$} \\
$\begin{array}{c}\text { Error in Azimuth } \\
\text { Michalsky }\end{array}$ & -0.065 & 0.206 & 0.150 & {$[-1.9031 .344]$} \\
$\begin{array}{c}\text { PAS Algorithm } \\
\begin{array}{c}\text { Sun Vector Deviation } \\
\text { Michalsky }\end{array}\end{array}$ & 0.000 & 0.177 & 0.127 & {$[-1.5531 .443]$} \\
PAS Algorithm & -0.208 & 0.110 & 0.086 & {$[0.0000 .667]$} \\
\hline
\end{tabular}


In 2007, Chen presents a solar sensor algorithm based on a principle of measurement and optical non-linear compensation. In a traditional analog solar sensor (Figure 13(a)), a thin mask with a square opening (Figure 13(b)) is placed above a quadrant of the detector. The incident sunlight illuminates different positions of the detector according to the angle and in relation to the main shaft of the sensor, projecting an image in plane of the detector. The signal generated by each quadrant, (i.e. S1, S2, S3 and S4) (Figure 13(a)), is directly proportional to the lighted area within the quadrant. Thus, in traditional analog solar sensor, the solar elevation and azimuth angle, $\alpha$ and $\beta$, are obtained by a signal processing scheme in accordance with the basic geometric principles, namely [53] [54]:

$$
\begin{gathered}
\alpha=\tan ^{-1}\left(\frac{L}{h}, M\right),|M| \leq \frac{L-a}{2 L}, \\
\beta=\tan ^{-1}\left(\frac{L}{h}, N\right),|N| \leq \frac{L-a}{2 L}, \\
M=\frac{S_{1}+S_{4}-\left(S_{2}+S_{3}\right)}{S_{1}+S_{2}+S_{3}+S_{4}}, N=\frac{S_{3}+S_{4}-\left(S_{1}+S_{2}\right)}{S_{1}+S_{2}+S_{3}+S_{4}},
\end{gathered}
$$

where $L$ is the average length of the square opening, $h$ is the distance between the mask and the plane of the detector and $a$ is the slit width.

However in Equations (1) and (2) the output signal of $M$ and $N$ depends on $\alpha$ e $\beta$ inputs, respectively, that is, the sensitivity of the sensor depends on the angle of incidence of sunlight. To solve this problem, the author replaced the opening shown in Figure 13(c). Thus the linear displacement of image projection in the detector caused by linear changes in the angle of incidence of sunlight was offset by the extra area. The experimental results showed that the sensor has a precision of $0.2^{\circ}$ throughout the field of view and $\pm 62^{\circ}$ for both axes [53] [54].

In 2009, Chong presents a general formula for axis tracking systems. The research discusses that the solar elevation angle and azimuth are among the most commonly used tracking mechanisms yet over the last few

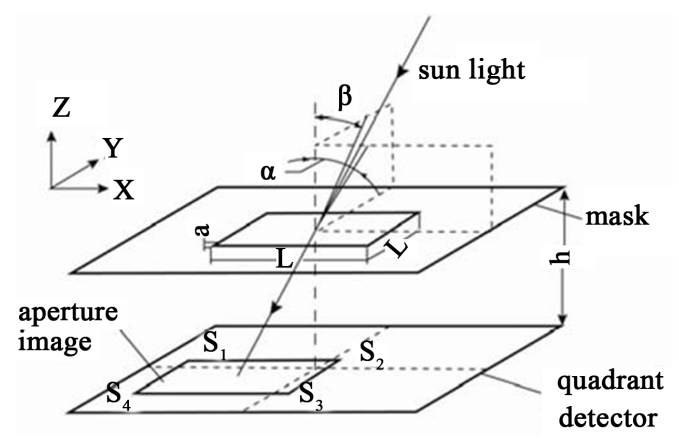

(a)

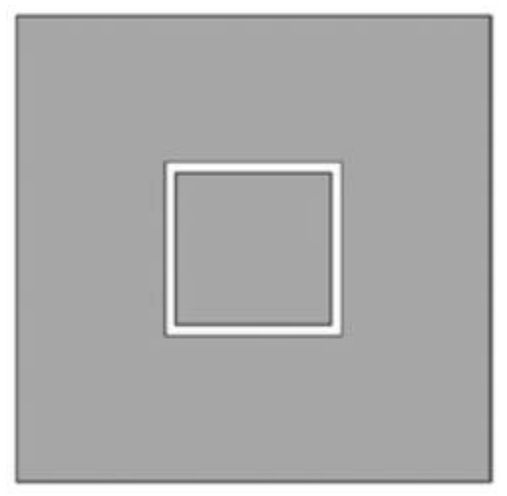

(b)

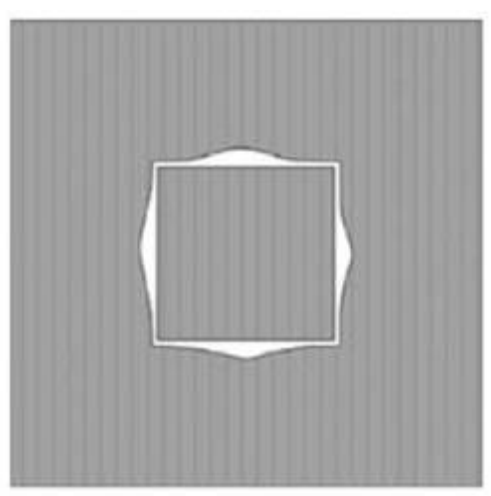

(c)

Figure 13. (a) Operating principle of a traditional analog solar sensor; (b) Opening of traditional analog solar sensor; (c) Opening proposal for the solar sensor analog [54]. 
decades these two tracking methods had their own formulae and were not interrelated. A general formula involving all possible methods is presented. This tracking formula not only provided a general mathematical solution, but more significantly, it improved the tracking accuracy by resolving installation errors [55].

In 2010, Tejwani developed a tracking system with an automatic cleaning system $360^{\circ}$ for PV modules. This automated system was implemented using a PIC8051 microcontroller that controls a stepper motor with a gear box. This mechanism does not require any sensors or synchronization. For the cleaning of PV modules, a sliding brush mechanism was developed. In this mechanism, the PV modules perform a rotation of $360^{\circ}$ in one day, which results in activation of cleaning brushes twice in PV modules. In terms of power generation, the cleaning scheme provides about 30\% more energy production, compared to the fixed PV module and about 20\% more energy production in comparison with the PV module with tracking using an axis [56].

In 2011, Sebastijan presents a new method to determine the maximum efficiency in the trajectory of the open-loop tracking systems, considering the energy consumption by the tracking system. The results show an increase in the electricity produced by the PV system in tracking trajectories determined by the proposed method. However, it represents a central component for maximum efficiency of the tracking system, where the sky is monitored through the cameras. Based on the forecast of movement of clouds and the energy consumption of the tracking system, the solar elevation and azimuth angle were determined in order to achieve maximum power gain, even during overcast days. This approach would eliminate the disadvantages existing in the open circuit monitoring systems with hourly changes according to variations of the solar elevation and azimuth angles, where the consumption of the tracking system is many times greater than the energy gained through the tracking system [1].

Furthermore, in 2013, Rizal presents a tracking system using a solar position algorithm. The simulations were performed by evaluating and modifying the source code with local parameters enrolled in the program. From the simulation results, the angle of solar elevation and azimuth, for an entire year (Jan-Dec 2012), were estimated. By integrating Control Area Network (CAN) communication modules and PV systems can be remotely controlled, which is vital for various applications of PV systems [57].

In 2014, Nadjah proposes a new design and development of a tracking system based on PIC30F6014A microcontroller. The advantage of this design is the low cost and low power consumption by the electronic circuits. The mechanical structure is designed to allow control of the rotational movements (azimuth and solar elevation) for only a DC motor. The control circuit is designed with several sensor units (temperature, irradiation and angle) with the possibility to store daily data measurements, which may be useful for evaluating system performance [58].

In the same year, Engin presents a tracking system with low power consumption. The electronics of this tracking device consists of a DC motor driven by a microcontroller core. The control algorithm developed in real time combines open-loop and closed-loop control methods to improve the performance and reliability of the tracking. The microcontrolled core computes the angle of inclination of PV module, in order to investigate the solar elevation angle. This technique of positioning reduces the error in finding the azimuth and solar elevation angle to $0.1^{\circ}$. The proposed tracking system has increased the energy produced by $40.7 \%$ [59].

Loschi developed a tracking system through a microcontrolled timing logic, sending commands to a linear actuator that moves the system. The tests focused in the comparisons between the prototype of the project, called Sunflower, and fixed PV modules. The results showed that the prototype of the Sunflower is more efficient in relation to fixed PV panels. From the comparison analysis of the results obtained, it was possible to observe a gain in efficiency of 31\%, with a variation of $\pm 0.8 \%$ in the Sunflower against fixed PV modules [60].

Recently, Chen presented an implementation of Taguchi-chaos-PSO (Particle Swarm Optimization) on Field Programmable Gate Array (FPGA) for tracking systems. The FPGA was used in conjunction with a NI 9642 controller to integrate the two-axis tracking system with Maximum Power Point Tracker (MPPT), effectively increasing the output power of PV modules. The two-axis tracking system uses the Particle Swarm Optimization (PSO) to find the parameters of the PI controller. The Taguchi-chaos-PSO method is proposed to improve the convergence of the stationary state of PSO. The MPPT uses fuzzy logic helping the PV module to achieve maximum power quickly and in an stable way. The experimental results suggest that the fuzzy logic can adjust the maximum power point quickly, keeping the dynamic response of the motor and sensor signal within range of control; thus, proving that this system has many smart functions that can determine quickly and accurately the solar position [61]. 


\section{Prediction of Irradiation}

A cloud is an aggregation of suspended particles of water, ice, or both, that are in sufficient concentrations to be visible. The term "cloud” also includes clouds that are nearly invisible to the human eye, but are easily detectable on satellite thermal imagery. Clouds are usually defined according to the phases of water and temperature of your top, being classified on the basis of: (1) genera, which is the main feature of the shape of a cloud, (2) species, which depend on the particularities in shape and differences in the internal structure of a cloud, (3) varieties, which define the special features of the arrangement and transparency of a cloud, (4) additional features and accessories, where the smaller cloud shapes are linked to the part of a main cloud and (5) mother cloud, which defines the source of a cloud, in cases where the cloud is formed from another cloud [10].

In addition to the standard system of genus and species of clouds, the World Meteorological Organization (WMO) also classifies the altitude clouds and divides the troposphere vertically into three levels; low, medium and high. Each level is defined by a series of vertical elevations in which each type of cloud typically appears, although the solar elevation of clouds depend on polar region of observation, as presented in Table 2 [10].

Clouds are divided into ten types, as shown in Figure 14, and can be classified as [10]:

- High-level clouds: Cirrus (Ci), Cirrocumulus (Cc) and Cirrostratus (CS). Are typically thin and white in appearance, but can appear in a magnificent variety of colors when the sun is low on the horizon;

- Mid-level clouds: Altocumulus (Ac), Altostratus (As), and Nimbostratus (NS). Are composed mainly of water droplets; however, they can also be composed of ice crystals when temperatures are low enough;

- Low-level clouds: Cumulus (Cu), Stratocumulus (SC), Stratus (St), and Cumulonimbus (Cb). Composed of water droplets.

In addition to the ten main types of clouds, fog and traces of inversion from airplanes should also be considered. Even if the features are similar to the clouds, the origins are different [10].

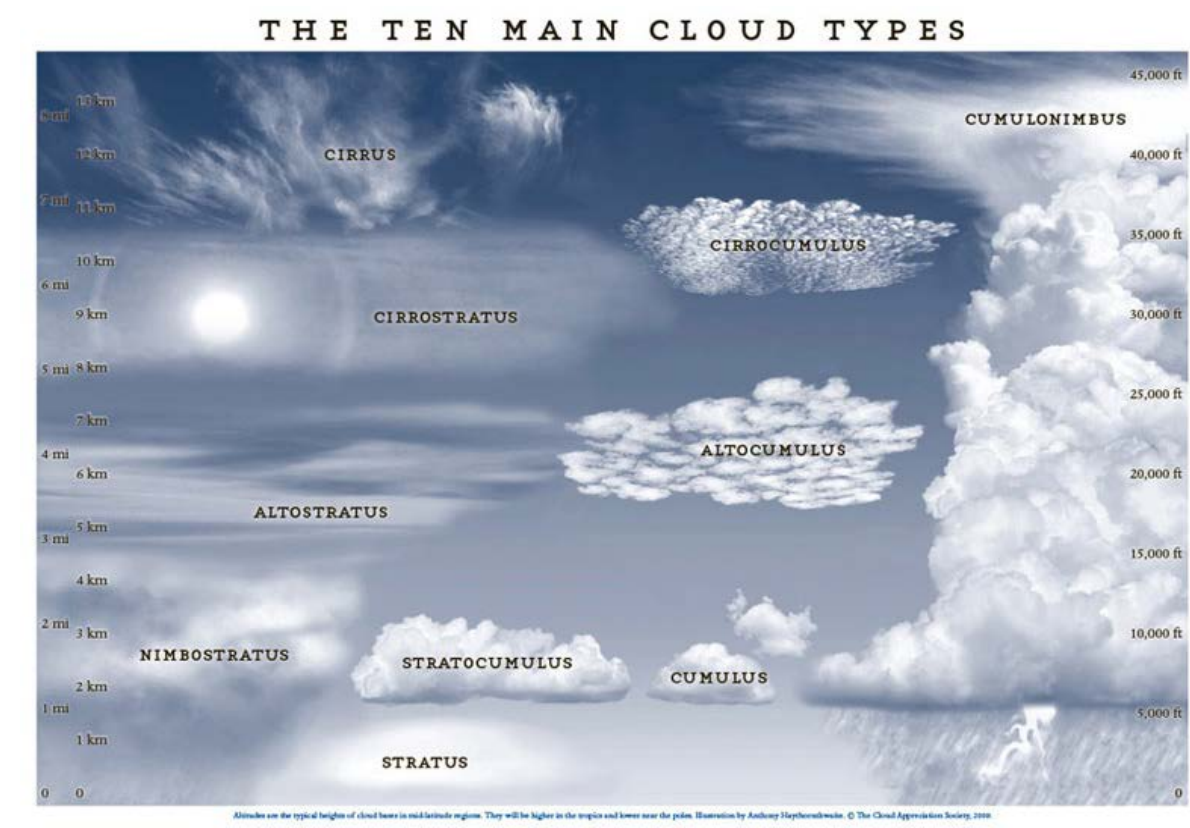

Figure 14. The top ten types of clouds (Cloud Appreciation Society, website) [10].

Table 2. Classification of clouds based on their altitudes for different polar regions (Ahrens, 2009, NOAA—National Weather Service, website) [10].

\begin{tabular}{cccc} 
Level & Polar region & Temperate region & Tropical region \\
High clouds & $3-8 \mathrm{~km}$ & $5-13 \mathrm{~km}$ & $6-18 \mathrm{~km}$ \\
Middle clouds & $2-4 \mathrm{~km}$ & $2-7 \mathrm{~km}$ & $2-8 \mathrm{~km}$ \\
Low clouds & Surface- $2 \mathrm{~km}$ & Surface-2 km & Surface-2 km \\
\hline
\end{tabular}


Many measuring instruments are used to obtain the data required for classification of clouds. Ground instruments are mainly used to measure the data from a specific place, while satellites are used to measure data on the continents. Ground instruments reach a small field of view, which limits the ability of cloud formation and monitoring of its movement over a large area of the sky. However, since the state of sky at the site is measured, they provide precise solar irradiance variations, due to clouds [10].

On the other hand, the satellites provide a large range of information from the clouds with multispectral measurements by different sensors, but the data provided are in low resolution and may contain errors: small clouds are often neglected due to the limited analysis and low clouds or thin are not easily identified. The cost of the equipment is a major factor for measurements of clouds, whereas the use of satellites is much more expensive than most ground instruments. However, some surface weather observation systems, such as radars are also expensive as satellites [10].

The following sections of this chapter presents an overview of measuring equipment for classification of clouds more used for the prediction of irradiation in PV systems, classified as: ground instruments and integrated instruments in the satellite.

A. Ground Instruments

Ground instruments are used to detect clouds in the sky at a specific location, though it can be integrated on a moving vehicle, and can be divided into three groups. The first group includes the irradiance meters that measure the diffuse and direct irradiation and radiometers that measure the incidence of Irradiation an electromagnetic spectrum and specific location. The second group includes cameras that photograph the state of sky in spectra: visible (VIS), infrared (IR) and ultraviolet (UV). The third group includes radars that measure the electromagnetic signal of instruments [10].

\section{A.1. Irradiance meters}

The first category of irradiance meters equipment includes instruments that measure irradiation received on site; pyranometers, pyrheliometers, pyrradiometers, photometers, pyrometers, and IR radiometers. The concept of use of these instruments is based on the fact that all objects have a temperature above absolute zero and radiate electromagnetic Irradiation due to their molecular oscillations. As the temperature of an object increases, these oscillations become more intense and the increase of irradiation and the spikes emitted at wavelengths, become gradually shorter. This results from the fact that everything in nature has a distinct spectral signature of reflected irradiation, emitted and absorbed. This signature allows the distinction of different objects such as the sun, clouds, molecules from the sky, land, sea, ice, and buildings. The measurement of electromagnetic irradiation spectra in VIS, IR, and UV is called radiometry; and the measuring instruments are called radiometers, although each instrument has a different name according to the spectrum of measurement. For instance, there are UV radiometers, IR radiometers, and MW (micro wave) radiometers. Moreover, spectroradiometers are systems of automatic radiometers that scan on a predefined range; this phased process allows measurements of multiple wavelengths using only one device. Depending on your spectral range, they are named IR specroradiometers, UV spectroradiometers, and spectrophotometers for visible light [10].

\section{A.2. Cameras}

Another category of the measuring equipment is the cameras that photograph the state of sky in the visible spectrum of IR or UV. The cameras detect the visible spectrum and classify clouds based on color and intensity differences between the different types of clouds and the sky (or ground). The camera's IR classification process is based on the difference in reflection and IR thermal irradiation from different types of clouds and sky (or ground), subject to the measured brightness temperature $\left(T_{b}\right)$. Brightness temperature is a descriptive measure of irradiation in terms of the temperature of a black body hypothetically emitting an identical amount of irradiation on the same wavelength. The brightness temperature is obtained by applying the inverse of the Planck Function to measure irradiation [10].

The camera's UV process is based on the difference in absorption of UV irradiation of different classes of clouds and correlating the reduction or increase of UV irradiance measured due to the presence of clouds [10].

A.3. Radiosondes

The last type of equipment used for detection of clouds is the radiosonde, a device with several electronic instruments integrated into a weather balloon. A balloon is filled with helium or hydrogen to reach altitudes of over $30 \mathrm{~km}$ at a speed of around $5 \mathrm{~m} / \mathrm{s}$. The package which comprises the radiosonde contains various sensors that measure temperature, air pressure and relative humidity in relation to the elevation of the clouds. During the elevation of the balloon, the radiosonde detects clouds, collecting information about the elevation of the base of 
clouds and higher thickness of the clouds. A big advantage the radiosonde is its ability to detect multilayer clouds through all levels of the atmosphere. The measurements are then transmitted to a receiver. In addition, the horizontal offset of the balloon is an indication of the wind speed and direction in particular layers of the atmosphere. During the last years, a global positioning system (GPS) was also integrated into the probe packet radio in order to track the exact movement of the balloon [10].

B. Satellite Integrated Instruments

There are numerous satellites that orbit the Earth with different purposes, some are geostationary (around the Earth always monitoring the same area), while others are in polar orbit, either passing over both poles of the Earth, or having a synchronized orbit with the Sun, which passes over the same location at the same time every day. Weather satellites are satellites that have the main function to observe the climate on Earth. They have onboard a multi-radiometers instrument, called "an imager", which incorporates all the necessary equipment for passive or active measurement of VIS, reflection IR, thermal IR, UV and Micro Wave (MW), among other measurements. In order to capture these measurements, the images have several radiometer channels, using a different channel for each sensor to measure data at specific wavelength range. Remote sensing technology leads to a better development of the images through more spectral channels, higher resolution, and sensitivity; thus, the latest versions of satellites allow the manipulation of a wider data range through a greater amount of acquired images [10].

C. Irradiation Prediction Integrated into Photovoltaic Systems

Different methods, algorithms and models for the classification of clouds are used for the prediction of solar irradiation; some of these techniques are universal and can be used regardless of the technology available. However, other techniques can only be used exclusively for a specific methodology.

Among the most recent research, Achleitner proposed a Solar Irradiance Prediction System (SIPS). It is an infrastructure of sensing using a wireless sensor network (WSN) performing detection of solar irradiation for a power generation prediction. Figure 15 presents an overview of the SIPS architecture [62].

This research is one of the first works about implementation of wireless sensor networks for prediction of solar irradiation, making it possible to calculate the future values of energy production. Achleitner concludes that the individual images generated from the sky and the data of the pyranometer, both used for the prediction, are limited by problems like much reflection of light (for the generated sky images) and single measuring point (for the pyranometer). Another difficulty is the fact that the pyranometer is an expensive device (more than US\$ 2000). The research demonstrates that commercial light detection sensors (cheaper than US\$ 1) can be adapted to measure solar irradiation in real environments; furthermore, this data can be used to improve irradiation prediction. The authors evaluated temporal and spatial correlations between the power output of a solar power plant of $1 \mathrm{MW}$ and the values of the sensors registered in the SIPS infrastructure. For prediction, neural network models were used such as NAR (Nonlinear Autoregressive Neural Network without External Input) and NARX (Nonlinear Autoregressive Neural Network with External Input). The developed algorithm (Peak Matching Algorithm, or PMA) performs forecast with an average accuracy of $97.24 \%$, while reducing the NRMSE (Normalized Root Mean Square Error) on average 240\% when compared with the methods [62].

Murakami proposes an analysis on energy prediction methods produced in PV systems for different time horizons and their applications in smart grids. The research presents most of the methods used and their respective

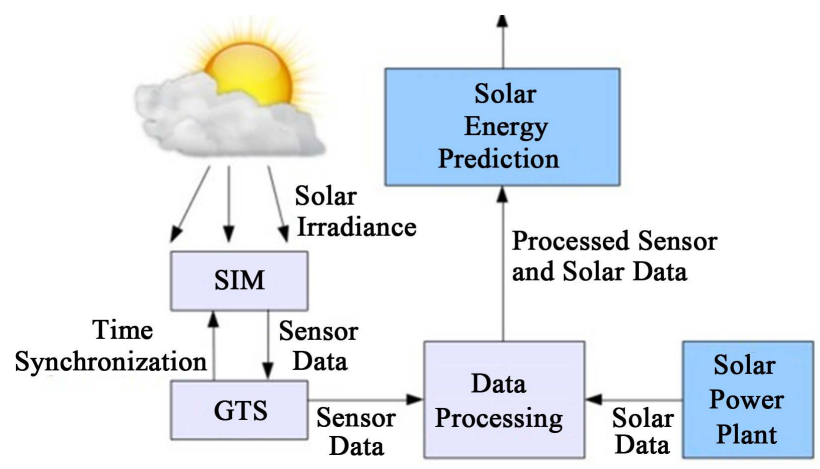

Figure 15. SIPS architecture overview [62]. 
times for the theoretical calculation of irradiation. It should be noted that the proposed method can predict the power output of a PV system in 30 minutes with a mean error of less than 5\%, estimate the effect of smoothing, and evaluate the rate of energy utilization system connected. This could be useful to supply, for example, electric vehicles [63].

Yoo and Kang developed a solar tracking system using fusion of astronomical estimates through the use of GPS with the generated image processing through cameras. Figure 16 presents a conceptual diagram of the proposed tracking system.

The proposed work focuses on using the results obtained with the processing of the images generated by the cameras for decision-making and tracking system, as well as it focuses on a proposal to distinguish the weather conditions between sunny or cloudy. Using this tracking method, the authors show that the module can maintain its position perpendicular to the solar irradiation. An algorithm is proposed to determine if the weather is sunny or cloudy. The variance is calculated by the position of the sun obtained by camera image. If the deviation is greater than the threshold preset, the authors conclude that it is cloudy. If the deviation is less than the threshold, it is concluded that it is sunny [64].

\section{Conclusions}

This research paper presents a review considering the main contributions of the past 40 years on the mechanisms and methods of tracking and prediction of irradiation in order to use in photovoltaic (PV) system for distributed electricity generation, applied to the concept of Feed in Tariffs. In this context, tracking and prediction systems can be widely used, depending on the precision of the incidence of solar irradiation prediction and gain in the production of electricity. It has been discussed that the mechanisms can be mainly classified as: active tracking, passive tracking and prediction systems. This review also presents a brief history about the development of tracking and prediction systems, detailing some aspects of performance evaluation, presenting information and the most relevant contributions of each research.

The use of passive tracking systems proves to be impractical for use in distributed generation of electricity; the main impediment relies on the dependence of an ideal thermodynamic process for the system's drive. The methods used are reviewed, showing a shortage of solutions, especially for distributed generation, compared with active systems and prediction.

Active tracking systems are viable for use in distributed generation of electricity and can be classified as either closed-loop or open-loop circuits. The methods presented have been reviewed and widely classified as: microprocessor-based and electro-optical sensor-based, auxiliary photovoltaic cells, and date and time algorithms.

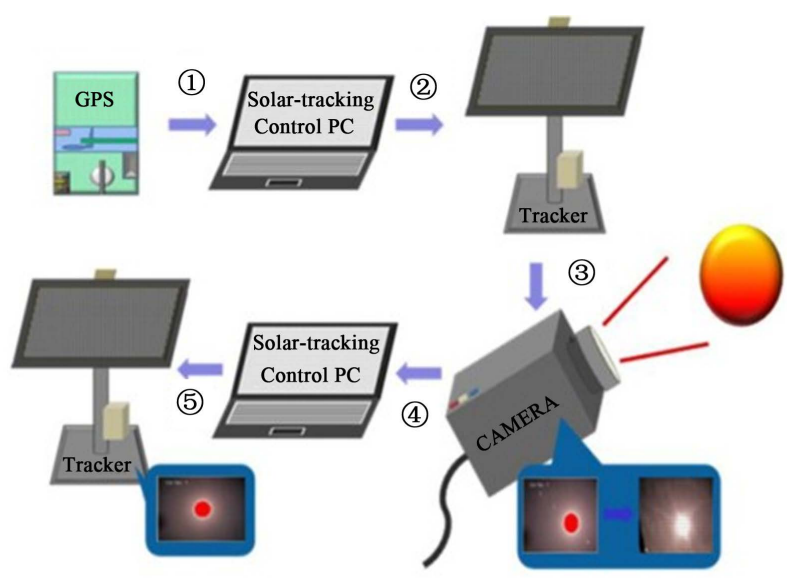

(1) Receive data from satellite using GPS.

(2) First correction angle of panel is produced.

(3) Obtain coordinates of sun with image sensor.

(4) Obtain weather information with image sensor.

(5) Second correction angle of panel is produced.

Figure 16. Conceptual diagram of the proposed tracking system in [64]. 
The control, development principles and performance of each method were revised, and the advantages and disadvantages presented systematically. However, it becomes apparent that the concern of most researchers converges in the energy consumption of these tracking systems. Open-loop systems have a lower consumption; however, their accuracy is much smaller compared with closed-loop systems. Closed-loop systems have high energy consumption due to the greater use of electronic components for the implementation of tracking methods and, most often, they are two-axis systems. Overall, the results presented in this review confirm the applicability of active tracking systems for a wide range of applications and with the concept of distributed generation.

Prediction systems integrated within photovoltaic (PV) systems offer a smarter solution, when compared with active systems, to reduce the power consumption of the overall system and to predict the energy generated on site. This forecast is possible through modern and advanced measurement equipment to allow the classification of clouds, from cameras, image generators (VIS, IR, UV and MW) and solar irradiation sensors. These instruments can be classified as either ground or satellite integrated. Prediction systems present one of the best technological solutions to enable the distributed generation through photovoltaic (PV) systems.

\section{Acknowledgements}

The authors would like to thank the Coordenação de Aperfeiçoamento de Pessoal de Nivel Superior (CAPES), the Consenho Nacional de Desenvolvimento Científico e Tecnológico (CNPq), the Fundação de Amparo à Pesquisa do Estado de São Paulo (FAPESP), the Departamento de Comunicações (DECOM), the Faculdade de Engenharia Elétrica e de Computação (FEEC) and the Universidade Estadual de Campinas (Unicamp), for their support in the development of this research.

\section{References}

[1] Seme, S., Stumberger, G. and Vorsic, J. (2011) Maximum Efficiency Trajectories of a Two-Axis Sun Tracking System Determined Considering Tracking System Consumption. IEEE Transactions on Power Electronics, 26, 1280-1290. http://dx.doi.org/10.1109/TPEL.2011.2105506

[2] Prinsloo, G. and Dobson, R. (2014) Solar Tracking: High Precision Solar Position Algorithms, Programs, Software and Source-Code for Computing the Solar Vector, Solar Coordinates. Sun Angles in Microprocessor, PLC, Arduino, PIC and PC-Based Sun Tracking Devices or Dynamic Sun Following Hardware. E-Book.

[3] Kitai, A. (2011) Principles of Solar Cells, LEDs and Diodes: The Role of the PN Junction. John Wiley \& Sons, Ltd., Chichester. http://dx.doi.org/10.1002/9781119974543

[4] Kalogirou, S. (2013) Solar Energy Engineering: Processes and Systems. 2nd Edition, Elsevier Inc.

[5] El-Adawi, M.K. and Al-Nuaim, I.A. (2007) The Temperature Functional Dependence of VOC for a Solar Cell in Relation to Its Efficiency New Approach. Desalination, 209, 91-96. http://dx.doi.org/10.1016/j.desal.2007.04.014

[6] Singh, P. and Ravindra, N.M. (2012) Temperature Dependence of Solar Cell Performance—An Analysis. Solar Energy Materials and Solar Cells, 101. 36-45. http://dx.doi.org/10.1016/j.solmat.2012.02.019

[7] Jazayeri, M., Uysal, S. and Jazayeri, K. (2014) Evaluation of Maximum Power Point Tracking Techniques in PV Systems Using MATLAB/Simulink. Proceedings of the Sixth Annual IEEE Green Technologies Conference (GreenTech), Corpus Christi, 3-4 April 2014, 54-60. http://dx.doi.org/10.1109/greentech.2014.21

[8] Cipriani, G., Di Dio, V., La Manna, D., Massaro, F., Member, R.M.I. and Zizzo, G. (2013) Economic Analysis on Dynamic Photovoltaic Systems in New Italian "Feed in Tariffs" Context. Proceedings of the 4th International Conference on Clean Electrical Power: Renewable Energy Resources Impact, Alghero, 11-13 June 2013, 584-590.

[9] Mousazadeh, H., Keyhani, A., Javadi, A., Mobli, H., Abrinia, K. and Sharifi, A. (2009) A Review of Principle and Sun-Tracking Methods for Maximizing Solar Systems Output. Renewable and Sustainable Energy Reviews, 13, 18001818. http://dx.doi.org/10.1016/j.rser.2009.01.022

[10] Tapakis, R. and Charalambides, A.G. (2013) Equipment and Methodologies for Cloud Detection and Classification: A Review. Solar Energy, 95, 392-430. http://dx.doi.org/10.1016/j.solener.2012.11.015

[11] Lee, C., Chou, P., Chiang, C. and Lin, C. (2009) Sun Tracking Systems: A Review. Sensors, 9, 3875-3890. http://dx.doi.org/10.3390/s90503875

[12] Tapakis, R.D. and Charalambides, A.G. (2013) Monitoring Cloud Motion in Cyprus for Solar Irradiance Prediction. Conference Papers in Medicine, 2013, 1-6. http://dx.doi.org/10.1155/2013/320618

[13] Zomewords Corporation (2014) Photovoltaic Tracking Racks. http://www.zomeworks.com/photovoltaic-tracking-racks/ 
[14] Poulek, V. (1994) Testing the New Solar Tracker with Shape Memory Alloy Actors. Proceedings of the Conference Record of the IEEE Photovoltaic Specialists Conference, Waikoloa, 5-9 December 1994, 1131-1133.

[15] Clifford, M.J. and Eastwood, D. (2004) Design of a Novel Passive Solar Tracker. Solar Energy, 77, 269-280. http://dx.doi.org/10.1016/j.solener.2004.06.009

[16] Castañeda, C.E.F. (2011) Desenvolvimento de um rastreador solar passivo por transferência de massa. Prodetec-Programa de Pós-Graduação de Desenvolvimento Tecnologico.

[17] McFee, R.H. (1975) Power Collection Reduction by Mirror Surface Nonflatness and Tracking Error for a Central Receiver Solar Power System. Applied Optics, 14, 1493-1502. http://dx.doi.org/10.1364/ao.14.001493

[18] Luque, A. and Andreev, V. (2007) Concentrator Photovoltaics. Springer, Berlin. http://dx.doi.org/10.1007/978-3-540-68798-6

[19] Zogbi, R. and Laplaze, D. (1984) Design and Construction of a Sun Tracker. Solar Energy, 33, 369-372. http://dx.doi.org/10.1016/0038-092x(84)90168-3

[20] Rumala, S.N. (1986) A Shadow Method for Automatic Tracking. Solar Energy, 37, 245-247. http://dx.doi.org/10.1016/0038-092X(86)90081-2

[21] Kalogirou, S.A. (1996) Design and Construction of a One-Axis Sun-Tracking System. Solar Energy, 57, 465-469. http://dx.doi.org/10.1016/S0038-092X(96)00135-1

[22] Khalifa, A.J.N. and Al-Mutawalli, S.S. (1998) Effect of Two-Axis Sun Tracking on the Performance of Compound Parabolic Concentrators. Energy Conversion and Management, 39, 1073-1079. http://dx.doi.org/10.1016/S0196-8904(97)10020-6

[23] Zeroual, A., Raoufi, M., Ankrim, M. and Wilkinson, A.J. (1998) Design and Construction of a Closed Loop SunTracker with Microprocessor Management. International Journal of Solar Energy, 19, 263-274. http://dx.doi.org/10.1080/01425919808914341

[24] Yousef, H.A. (1999) Design and Implementation of a Fuzzy Logic Computer-Controlled Sun Tracking System. Proceedings of the IEEE International Symposium on Industrial Electronics, Bled, 12-16 July 1999, 1030-1034. http://dx.doi.org/10.1109/isie.1999.796768

[25] Urbano, J.A., Matsumoto, Y., Asomoza, R., Aceves, F.J., Sotelo, A. and Jacome, A. (2003) 5 Wp PV Module-Based Stand-Alone Solar Tracking System. Proceedings of the 3rd World Conference on Photovoltaic Energy Conversion, Osaka, 18 May 2003, 2463-2465.

[26] Roth, P., Georgiev, A. and Boudinov, H. (2004) Design and Construction of a System for Sun-Tracking. Renewable Energy, 29, 393-402. http://dx.doi.org/10.1016/S0960-1481(03)00196-4

[27] Roth, P., Georgiev, A. and Boudinov, H. (2005) Cheap Two Axis Sun Following Device. Energy Conversion and Management, 46, 1179-1192. http://dx.doi.org/10.1016/j.enconman.2004.06.015

[28] Berenguel, M., Rubio, F.R., Valverde, A., Lara, P.J., Arahal, M.R., Camacho, E.F. and López, M. (2004) An Artificial Vision-Based Control System for Automatic Heliostat Positioning Offset Correction in a Central Receiver Solar Power Plant. Solar Energy, 76, 563-575. http://dx.doi.org/10.1016/j.solener.2003.12.006

[29] Huang, B.J. and Sun, F.S. (2007) Feasibility Study of One Axis Three Positions Tracking Solar PV with Low Concentration Ratio Reflector. Energy Conversion and Management, 48, 1273-1280. http://dx.doi.org/10.1016/j.enconman.2006.09.020

[30] Rubio, F.R., Ortega, M.G., Gordillo, F. and López-Martínez, M. (2007) Application of New Control Strategy for Sun Tracking. Energy Conversion and Management, 48, 2174-2184. http://dx.doi.org/10.1016/j.enconman.2006.12.020

[31] Chiang, C.-M., Lee, C.-Y. and Chou, P.-C. (2009) Solar Orientation Measurement Systems with Integrated Solar Cells. The Open Construction and Building Technology Journal, 3, 90-95. http://dx.doi.org/10.2174/1874836800903010090

[32] Huang, B.J., Ding, W.L. and Huang, Y.C. (2011) Long-Term Field Test of Solar PV Power Generation Using OneAxis 3-Position Sun Tracker. Solar Energy, 85, 1935-1944. http://dx.doi.org/10.1016/j.solener.2011.05.001

[33] Jeong, B.H., Park, J.H., Kim, S.D. and Kang, J.H. (2013) Performance Evaluation of Dual Axis Solar Tracking System with Photo Diodes. Proceedings of the International Conference on Electrical Machines and Systems (ICEMS), Busan, 26-29 October 2013, 414-417.

[34] More, V.P. and Kulkarni, V.K. (2014) Design and Implementation of Microcontroller Based Automatic Solar Radiation Tracker. International Journal of Current Engineering and Technology, 2, 230-234.

[35] Cinar, S.M., Hocaoğlu, F.O. and Orhun, M. (2014) A Remotely Accessible Solar Tracker System Design. Journal of Renewable and Sustainable Energy, 6, Article ID: 033143. http://dx.doi.org/10.1063/1.4885099

[36] Mumtahina, U., Bhuiya, M.M., Sayem, A.S., Azad, A. and Mohammad, N. (2014) Design and Performance of Multidimensional Automatic Solar Tracking System. International Journal of Energy Technology, 6, 1-6. 
[37] Yilmaz, S., Riza, H., Dogmus, O., Dincer, F. and Akgol, O. (2015) Design of Two Axes Sun Tracking Controller with Analytically Solar Radiation Calculations. Renewable and Sustainable Energy Reviews, 43, 997-1005. http://dx.doi.org/10.1016/j.rser.2014.11.090

[38] Cristian, G., Longo, M., Roscia, M. and Pagano, M. (2015) Comparative Analysis of Fixed and Sun Tracking Low Power PV Systems Considering Energy Consumption. Energy Conversion and Management, 92, 143-148. http://dx.doi.org/10.1016/j.enconman.2014.12.046

[39] Poulek, V. and Libra, M. (1998) New Solar Tracker. Solar Energy Materials and Solar Cells, 51, 113-120. http://dx.doi.org/10.1016/S0927-0248(97)00276-6

[40] Poulek, V. and Libra, M. (2000) Very Simple Solar Tracker for Space and Terrestrial Applications. Solar Energy Materials and Solar Cells, 60, 99-103. http://dx.doi.org/10.1016/S0927-0248(99)00071-9

[41] Abouzeid, M. (2001) Use of a Reluctance Stepper Motor for Solar Tracking Based on a Programmable Logic Array (PLA) Controller. Renewable Energy, 23, 551-560. http://dx.doi.org/10.1016/S0960-1481(00)00133-6

[42] Karimov, K.S., Saqib, M.A., Akhter, P., Ahmed, M.M., Chattha, J.A. and Yousafzai, S.A. (2005) A Simple PhotoVoltaic Tracking System. Solar Energy Materials and Solar Cells, 87, 49-59. http://dx.doi.org/10.1016/j.solmat.2004.08.010

[43] Poulek, V. and Libra, M. (2007) New Bifacial Solar Trackers and Tracking Concentrators. Earth, 4, 1-9.

[44] Kamala, J. and Joseph, A. (2014) Solar Tracking for Maximum and Economic Energy Harvesting. International Journal of Engineering \& Technology, 5, 5030-5037.

[45] Edwards, B.P. (1978) Computer Based Sun Following System. Solar Energy, 21, 491-496. http://dx.doi.org/10.1016/0038-092X(78)90073-7

[46] Al-Naima, F.M. and Yaghobian, N.A. (1990) Design and Construction of a Solar Tracking System. Solar \& Wind Technology, 7, 611-617. http://dx.doi.org/10.1016/0741-983X(90)90072-A

[47] Koyuncu, B. and Balasubramanian, K. (1991) A Microprocessor Controlled Automatic Sun Tracker. IEEE Transactions on Consumer Electronics, 37, 913-917. http://dx.doi.org/10.1109/30.106958

[48] Davies, P.A. (1993) Sun-Tracking Mechanism Using Equatorial and Ecliptic Axes. Solar Energy, 50, 487-489. http://dx.doi.org/10.1016/0038-092X(93)90110-A

[49] Al-Jumaily, K.E.J. and Al-Kaysi, M.K.A. (1998) The Study of the Performance and Efficiency of Flat Linear Fresnel Lens Collector with Sun Tracking System in Iraq. Renewable Energy, 14, 41-48. http://dx.doi.org/10.1016/S0960-1481(98)00045-7

[50] Michalsky, J.J. (1988) The Astronomical Almanac's Algorithm for Approximate Solar Position (1950-2050). Solar Energy, 42, 227-235. http://dx.doi.org/10.1016/0038-092X(88)90045-X

[51] Blanco-Muriel, M., Alarcón-Padilla, D.C., López-Moratalla, T. and Lara-Coira, M. (2001) Computing the Solar Vector. Solar Energy, 70, 431-441. http://dx.doi.org/10.1016/S0038-092X(00)00156-0

[52] Abdallah, S. and Nijmeh, S. (2004) Two Axes Sun Tracking System with PLC Control. Energy Conversion and Management, 45, 1931-1939. http://dx.doi.org/10.1016/j.enconman.2003.10.007

[53] Chen, F., Feng, J. and Hong, Z. (2006) Digital Sun Sensor Based on the Optical Vernier Measuring Principle. Measurement Science and Technology, 17, 2494-2498. http://dx.doi.org/10.1088/0957-0233/17/9/017

[54] Chen, F. and Feng, J. (2007) Analogue Sun Sensor Based on the Optical Nonlinear Compensation Measuring Principle. Measurement Science and Technology, 18, 2111-2115. http://dx.doi.org/10.1088/0957-0233/18/7/042

[55] Chong, K.K. and Wong, C.W. (2009) General Formula for On-Axis Sun-Tracking System and Its Application in Improving Tracking Accuracy of Solar Collector. Solar Energy, 83, 298-305. http://dx.doi.org/10.1016/j.solener.2008.08.003

[56] Tejwani, R. and Solanki, C.S. (2010) $360^{\circ}$ Sun Tracking with Automated Cleaning System for Solar PV Modules. Proceedings of the IEEE Photovoltaic Specialists Conference, Honolulu, 20-25 June 2010, 2895-2898.

[57] Rizal, Y., Wibowo, S.H. and Feriyadi (2013) Application of Solar Position Algorithm for Sun-Tracking System. Energy Procedia, 32, 160-165. http://dx.doi.org/10.1016/j.egypro.2013.05.021

[58] Nadjah, A., Kadri, B., Sellam, M., Guettatfi, Z. and Beddraoui, A. (2014) New Design of Dual Axis Sun Tracker with DSPIC Microcontroller. Proceedings of the 16th International Power Electronics and Motion Control Conference and Exposition, Antalya, 21-24 September 2014, 1030-1034. http://dx.doi.org/10.1109/epepemc.2014.6980644

[59] Engin, M. and Engin, D. (2014) Design of Real Time Embedded PID Controller for Sun Tracking Robot Manipulator. Proceedings of the IEEE/ASME International Conference on Advanced Intelligent Mechatronics (AIM), Besacon, 8-11 July 2014, 670-675.

[60] Loschi, H., Ferrarezi, R. and Rocha, N. (2014) Solar Tracking System Installed with Photovoltaic (PV) Panels to Con- 
nection Grid Tie Low Voltage (Sunflower). Energy and Power, 4, 49-53.

[61] Chen, J., Yau, H. and Hung, T. (2015) Mechatronics Design and Implementation of FPGA-Based Taguchi-Chaos-PSO Sun Tracking Systems. Mechatronics, 25, 55-64.

[62] Achleitner, S., Kamthe, A., Liu, T. and Cerpa, A. (2014) SIPs: Solar Irradiance Prediction System. Proceedings of the 13th International Symposium on Information Processing in Sensor Networks, Berlin, 15-17 April 2014, 225-236. http://dx.doi.org/10.1109/ipsn.2014.6846755

[63] Murakami, Y., Takabayashi, Y. and Noro, Y. (2014) Photovoltaic Power Prediction and Its Application to Smart Grid Time. Proceedings of the IEEE Innovative Smart Grid Technologies-Asia (ISGT Asia), Kuala Lumpur, 20-23 May 2014, 47-50.

[64] Yoo, J., Kang, Y., Song, B. and Song, J. (2014) Solar Tracking System Experimental Verification Based on GPS and Vision Sensor Fusion. Journal of Automation and Control Engineering, 2, 417-421. 